\title{
INTRODUCTION TO THE TOUCH PROJECTOR TECHNOLOGY
}

\author{
Kiran M Patil ${ }^{1}$, S.L. Lahudkar ${ }^{2}$ \\ ${ }^{1}$ Lecturer, E \&TC Department, JSPM's Imperial College of Engineering \& Research, Wagholi, Pune , Maharashtra, \\ India \\ ${ }^{2}$ Professor, E \&TC Department, JSPM's Imperial College of Engineering \& Research, Wagholi, Pune, Maharashtra,
} India

\begin{abstract}
The main motive of this paper is to describe touch projector technology and how it can be untilise. This paper's intention is to give information about new technology which allows projection on any surface using very small device. This paper also contains briefs history of touch projector technology and describes the review of resent devices used as touch projector. It also illustrates and focuses on their uses in conferences, education, entertainment and business. Additionally this paper also details about some point such as surface, return value and battery are required some enhancement.
\end{abstract}

Keywords: Touch Pico, Interactive Projector, Cicret Bracelet, Touch projector Devices.

\section{INTRODUCTION}

Touch projector is a technology allows user to operate content of device on any surface at distance. This allows interaction of human with digital world. Touch projector varies in size depends on resolution and space of display. It is compatible with Android and windows8 operating systems. It can use as projector on any suitable surface such as table, wall, white board, skin. Resent touch projectors can support low angle projection. User can interact with multitouch screen of projector using interface like touch pen, finger.

With Touch projector, user can operate using more than one interface on the same object e.g. both hands can be used. The non-dominant hand/interface holds the device and artlessly direct it, while the dominant hand/interface interacts within the reference frame established by the nondominant and this combination allows interaction with huge displays by moving the entire device as well as interaction with small displays using touch input. Touch Projector extract immediate feedback. When content on the target display is changed, users immediately recognize these changes through the live video. This allows a close connection of action and reaction as both occur on the mobile device.

\section{LITERATURE REVIEW}

Boring, S., Baur, D., Butz, A., Gustafson, S., \& Baudisch, P. [1] said: in 1992, Tani et al. put forward to remotely control the functioning of machines in a factory by controlling a live video image on a computer screen. Touch projector, a system that allows the users to interact with remote screens through a live video image on their mobile device. The handheld device tracks itself with reference to the surrounding displays.
Touch on the video image is "projected" onto the target display in view, as if it had occurred there. This literal adaptation of Tani's idea, however, this idea was failed because handheld video doesn't offer adequate stability and control to allow precise manipulation. Since then, many experts tried to fix this with a series of enhancements such as creating a separate device with its own operating system.

\section{DIFFERENT TOUCH PROJECTORS}

Touch Projector technology can be work as projector to any surface. This technology will help to fill up the gap between human and digital world. Now a day this technology is gaining the importance in digital technology world. This technology is under development stage and very few companies allow pre-order of these devices. International companies are working hard on reducing the size and improve the quality of these devices, as these devices has many feature and which attracts the consumers.

Initially keyboard projection was started using laser as interaction between the human and mobile or I-pod. Later interactive projectors were invented which were huge in size and wall mounted. These projectors need interactive screens or white board, these projectors operates by interface like touch pen and useful for the education purpose. Touch Pico projector were invented which are pocket size with additional feature such as HDMI, USB, AV. These projectors can be projected on any surface like wall, skin table. Cicret bracelet is the technology which allows low angle projection on skin only, User can use it as tablet screen

\subsection{Magic Touch Virtual Projection Keyboard:}

This types of devices are available known as magic cube projection keyboard company such as cellulon designs this keyboard projector. Basic design of this projector is shown in figure. The projection laser displays the layout onto any 
surface, keystrokes are recognized and relayed via an invisible infrared laser combined with an optical sensor. Process of reorganization works as: when user presses key on projected keyboard, the infrared layer is interrupted. This produces IR reflections that are recognized by sensor in three dimensions, allowing the system to assign a coordinate.

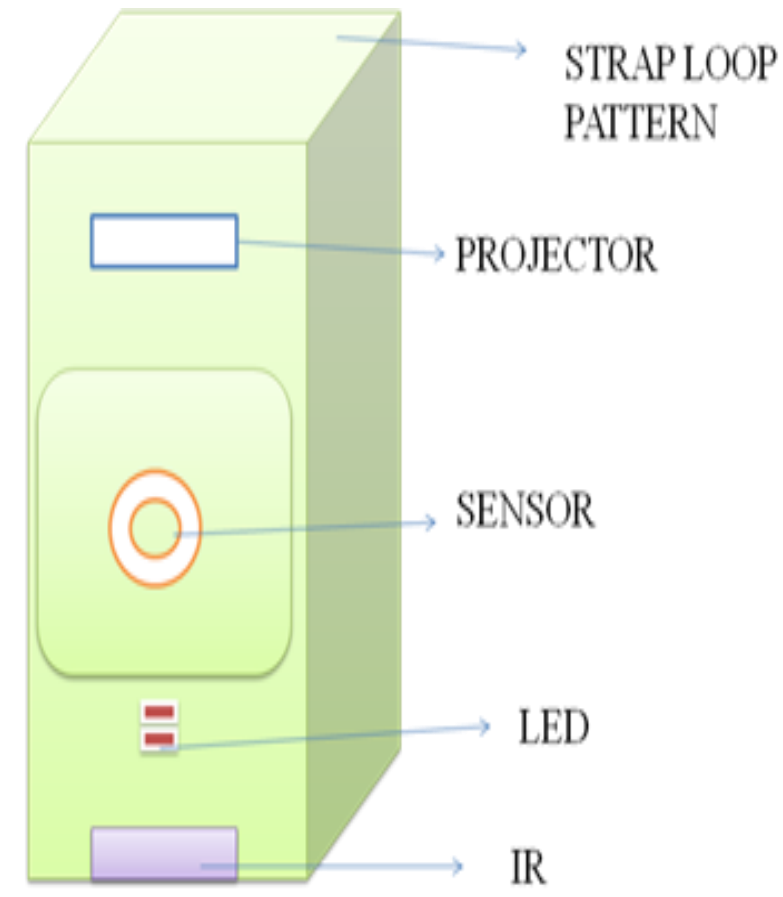

HOW MAGIC CUBE" WORKS

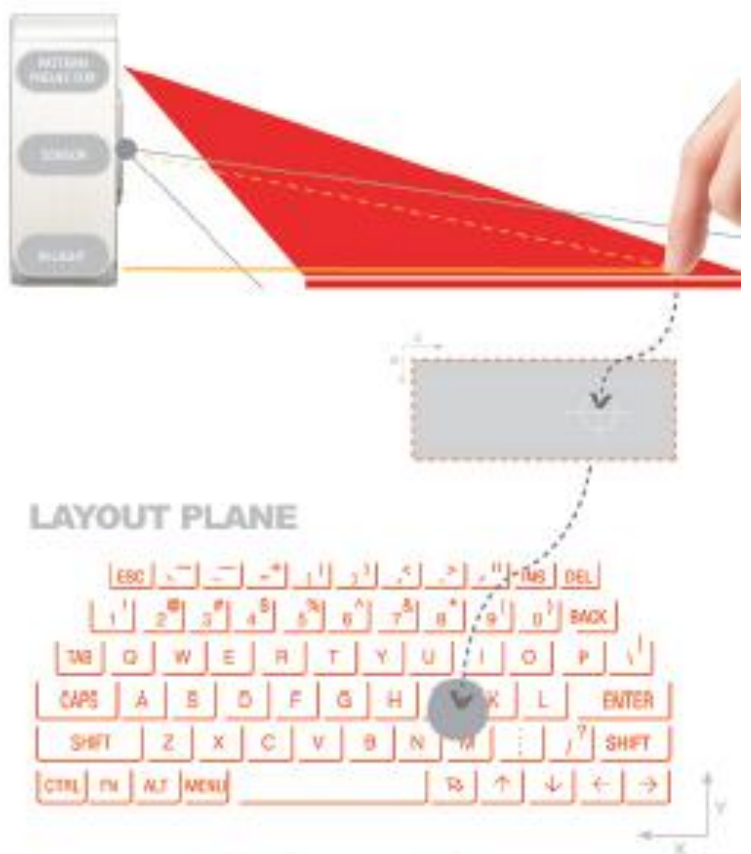

LIGHT

Fig 1.Basic design and working of cellulon Magic cube

\subsection{Interactive Projector:}

These projector is large in size, interactive screen that connects a computer and projector. These projector projects computer or laptops screen on interactive surface.
Interactive projectors replace the actual board with electronic pen or styluses that send wireless signals to the projector. The projector in turn, receive and send those signals to the computer, usually via USB cable.

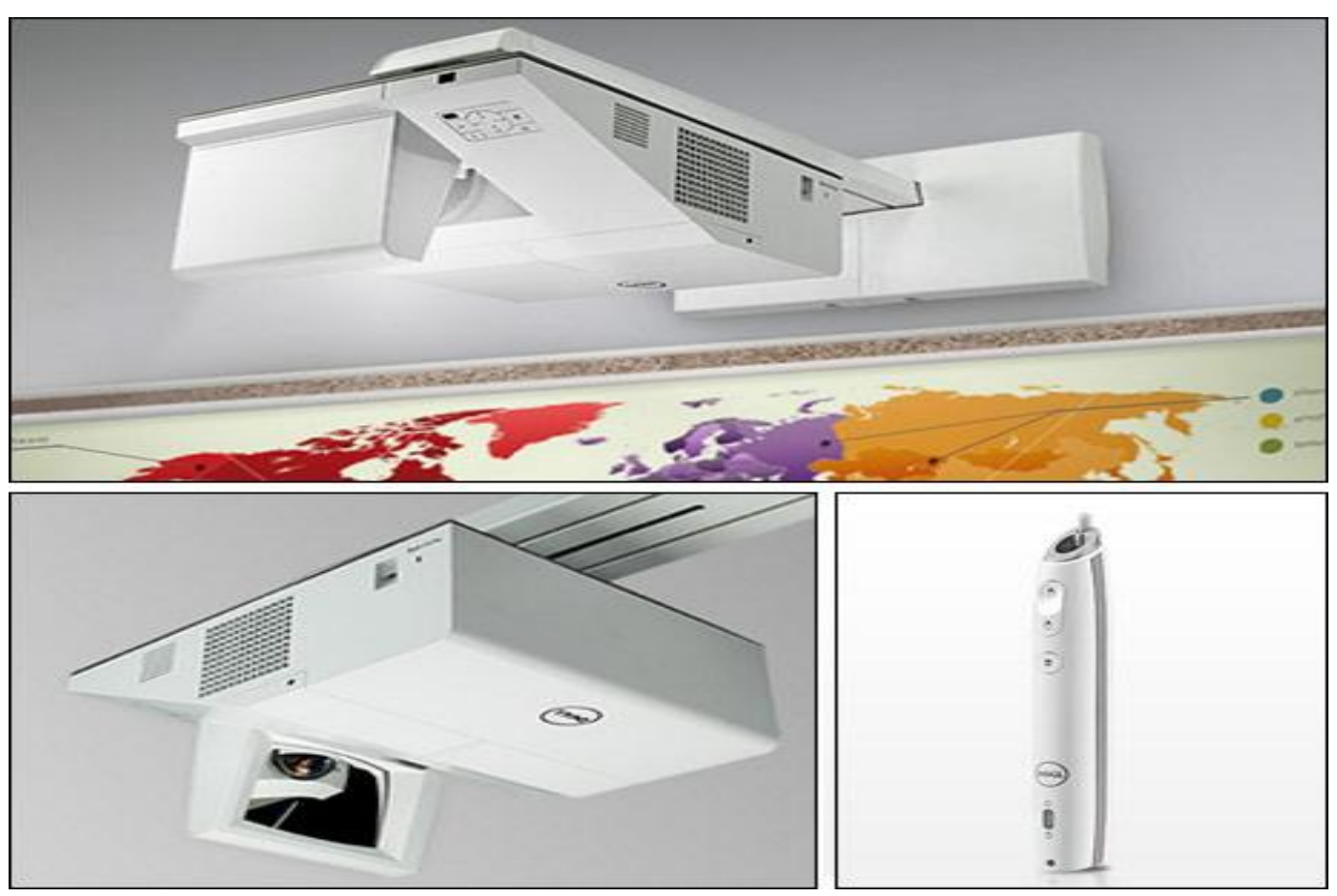

Fig 2.Dell S500wi projector 


\subsection{Touch Pico Projector:}

Pico projector is pocket sized projector which turns any surface into android touch screen..

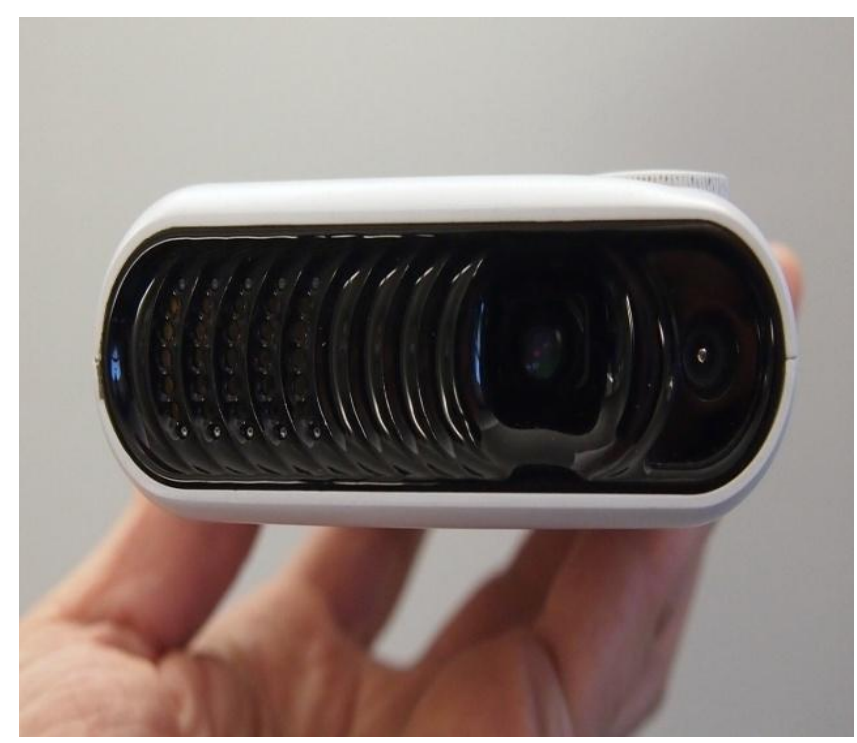

Front view of Touch Pico

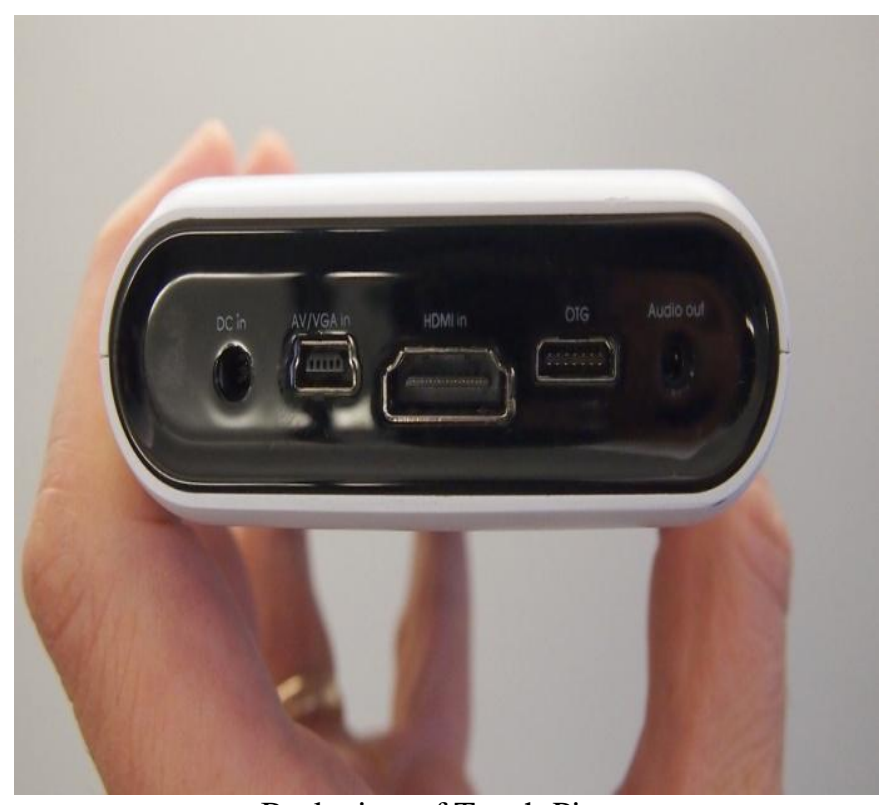

Back view of Touch Pico

This device wirelessly projects display from android Smartphone's, with touch interface. It is an handheld projector which has ability to turn any flat surface into an interactive screen

\subsection{Cicret Bracelate :}

This is latest technology of touch projector which skin as projection surface. User can operate mobile on skin. It is consist of pico projector , 8 long range proximity sensor, accelerometer, vibrator, snap button, $\mathrm{WiFi}$ and Bluetooth. Touch pico projector projects mobile screen on users skin then sensor detects fingers position and sends information to bracelate having connectivity with mobile.
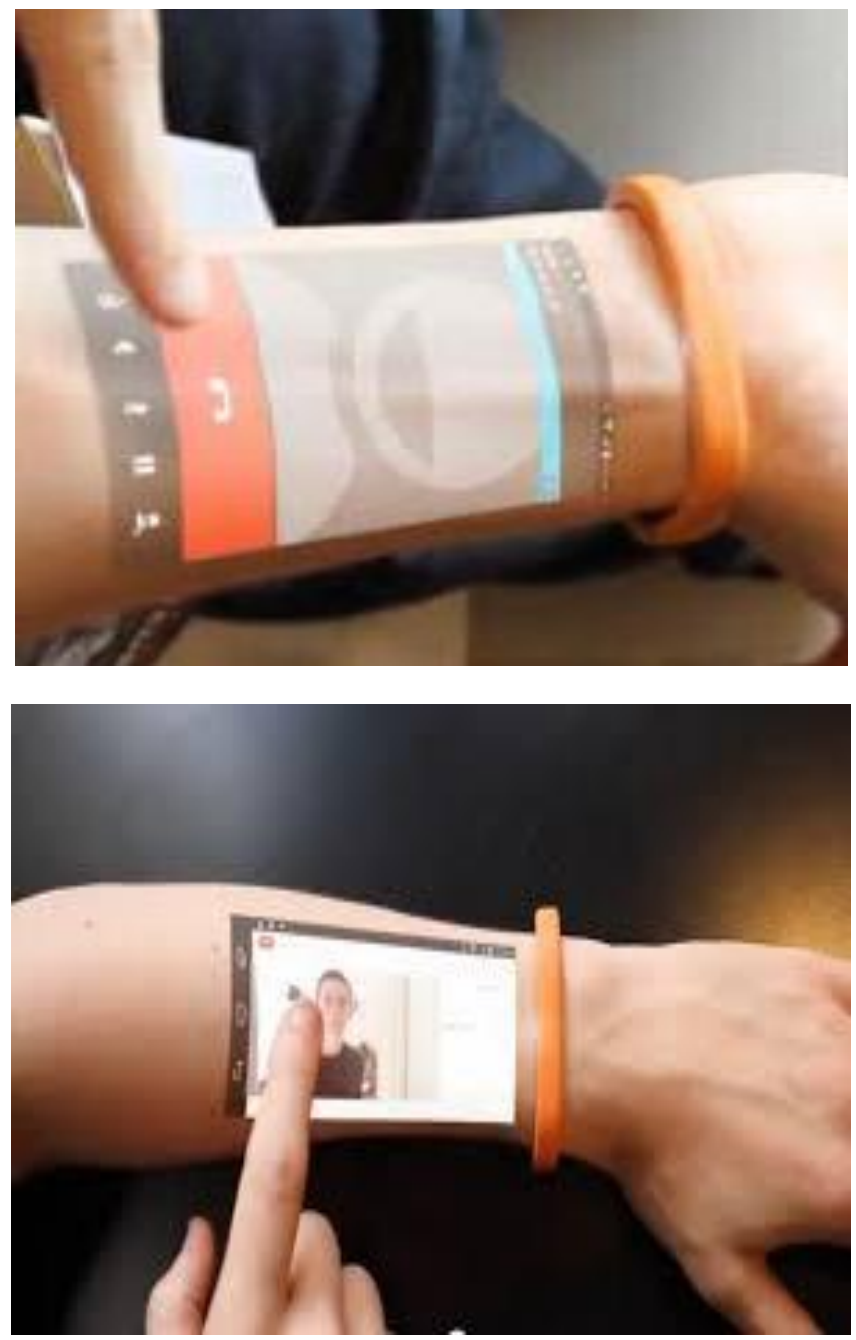

Fig 3.Image showing Cicret Bracelet

\section{COMPRESSION SPECIFICATION}

Touch projector technology made life simple and smooth and that allows us to perform task that could not do using other projectors. List of advantages of this technology would be very extended. As we know that every inventions has own weakness. The following discussion includes some specifications comparison of products of different companies of touch projector.

Firstly, touch projector technology is not an essential nor there is an immediate requirement of it. It makes teacher's or a businessman's lives more difficult. The cost of this technology is not in the price, but in which extent user requirements and how to simplify everyday life against the monetary value paid. There are many applications of touch projector devices in the field of entertainment and gaming, but when it comes to paying the money, one will consider whether the device is worth the money.

Dell Interactive Projector which has its whiteboard and two styluses with screen size 100". The resolution is high at $1280 \times 800$ that the display is clear enough even with the sunlight seeping into the classroom early in the morning. Interactive projectors not useful for personal prepose 
because it is not very costly but heavy so difficult to carry. We can use touch pico projector instead of interactive projector it is pocket-sized easy to carry. Touch projector projects screen on any surface bur display specification changes with type of surface such as dark or hairy skin not able to offer true colour on there skin. Touch projector has not its own operating system it supports for downloading apps from google play store. Cicret bracelet has difficulty in establishing connection.

Table 1. Specification compression of different touch projector

\begin{tabular}{|c|c|c|c|c|}
\hline Criteria & $\begin{array}{l}\text { Cellulo } \\
\text { n Magic } \\
\text { Cube }\end{array}$ & $\begin{array}{l}\text { Dell } \\
\text { Interactive } \\
\text { Projector }\end{array}$ & $\begin{array}{l}\text { Touch } \\
\text { Pico }\end{array}$ & $\begin{array}{l}\text { Cicret } \\
\text { Bracele } \\
t\end{array}$ \\
\hline Cost & $\$ 220.79$ & $\$ 4.129$ & $\begin{array}{l}\$ 450- \\
\$ 600\end{array}$ & $\begin{array}{l}\$ 600- \\
\$ 700\end{array}$ \\
\hline Availability & Yes & Yes & Yes & $\begin{array}{l}\text { Pre- } \\
\text { order }\end{array}$ \\
\hline Weight & $113 \mathrm{~g}$ & $\begin{array}{l}\text { Projector: } \\
8.5 \mathrm{~kg} \\
\text { Wall } \\
\text { mount: } \\
5.94 \mathrm{~kg} \\
\text { Whiteboar } \\
\mathrm{d}: 25.1 \mathrm{~kg} \\
\text { Laser } \\
\text { curtain } \\
309 \mathrm{~g}\end{array}$ & $\begin{array}{l}130 \text { to } \\
150 \\
\text { grams }\end{array}$ & - \\
\hline Wi-Fi & No & Yes & Yes & Yes \\
\hline Bluetooth & No & Yes & Yes & No \\
\hline $\begin{array}{l}\text { Native } \\
\text { Resolution }\end{array}$ & - & $70 "-100 "$ & $\begin{array}{l}12 "- \\
80 "\end{array}$ & - \\
\hline Battery & Built-in & No & Built-in & Yes \\
\hline $\begin{array}{l}\text { Supporting } \\
\text { Input }\end{array}$ & No & $\begin{array}{l}\text { AV,HDMI, } \\
\text { USB Input, } \\
\text { VGA Input }\end{array}$ & $\begin{array}{l}\text { AV, } \\
\text { HDMI } \\
\text { Input }\end{array}$ & No \\
\hline $\begin{array}{l}\text { Internal } \\
\text { Memory }\end{array}$ & No & $2 \mathrm{G}$ & $4 G$ & - \\
\hline $\begin{array}{l}\text { External } \\
\text { Memory }\end{array}$ & No & $\begin{array}{l}\text { 32GB USB } \\
\text { flash drive }\end{array}$ & $\begin{array}{l}16 \mathrm{~GB} \\
\text { SD } \\
\text { card }\end{array}$ & SD card \\
\hline $\begin{array}{l}\text { Screen } \\
\text { Distance }\end{array}$ & - & $0.51-0.76 \mathrm{~m}$ & $0.5-6 \mathrm{~m}$ & $1 \mathrm{~cm}$ \\
\hline $\begin{array}{l}\text { Aspect } \\
\text { Ratio }\end{array}$ & - & $16: 10$ & $16: 9$ & - \\
\hline Brightness & $\begin{array}{l}\text { Facility } \\
\text { of } \\
\text { adjustm } \\
\text { ent }\end{array}$ & $\begin{array}{l}3,100 \\
\text { ANSI } \\
\text { lumens }\end{array}$ & $\begin{array}{ll}\text { Up } & \text { to } \\
80 & \end{array}$ & - \\
\hline $\begin{array}{l}\text { Operating } \\
\text { system }\end{array}$ & No & No & $\begin{array}{l}\text { Androi } \\
\text { d } 4.4\end{array}$ & - \\
\hline
\end{tabular}

\section{CONCLUSION AND FUTURE WORK}

From above discussion we can say that there is still scope of improvement in touch projector technology. Many companies are doing hard work for improving this technology. This prototype has not its own operating system. Weakness like surface used for display, size is area for improvement in this technology. Sixthsence is upcoming technology to overcome problem with touch projector technology. This technology is gesture interface it contains data projector and camera.

\section{REFERENCES}

[1]. Boring, S., Baur, D., Butz, A., Gustafson, S., \& Baudisch, P. (2010). Touch projector: mobile interaction through video. SIGCHI Conference on Human Factors in Computing Systems (CHI'10), 2287-2296.

[2]. The Cicret Bracelet: It's like a tablet...but on your skin! (n.d.). Retrieved December 05, 2014, from http://www.cicret.com/wordpress/?page_id $=17920$

[3]. Touchjet. (n.d.). Retrieved December 05, 2014, from http://www.atouchjet.com/

[4]. TouchPico: Turn Any Surface Into A Touch Screen | Indiegogo. (n.d.). Retrieved December 05, 2014, from http://tinyurl.com/k3pcvpm

[5]. Dell. (n.d.). Dell Interactive Projector | S520. Retrieved from http://tinyurl.com/le64sp4

[6]. Tsai, C. J. (n.d.). 3D \& Mobile Interactive Projection Hot Topics of LED in Display.

[7]. Touchjet. (n.d.). Retrieved December 05, 2014, from http://www.atouchjet.com/

[8]. The Cicret Bracelet: It's like a tablet...but on your skin! (n.d.). Retrieved December 05, 2014, from http://www.cicret.com/wordpress/?page_id=17920

[9]. TouchPico: Turn Any Surface Into A Touch Screen | Indiegogo. (n.d.). Retrieved December 05, 2014, from http://tinyurl.com/k3pcvpm 